\title{
THE APPROACH OF IBN TABATIBA AL-ASBAHANI TO THE ISSUE OF WORD AND MEANING CASTING AND THE PROBLEMATIC ARTISTIC IMAGERY
}

\author{
Mohammad Majid Ad-dakhil
}

Email: mhamad_dakeel@Yahoo.com

Jordan- Irbid- Irbid University College (BAU)

Alamat Korespondensi: Depertement of Basic Sciences- Devision of The Arabic language and

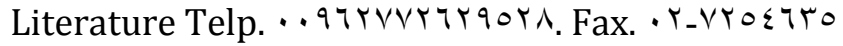

\begin{abstract}
Abstrak: This study shows that intends to address the issue of "word-meaning" as addressed in work "iyar al syi'r", in addition to the issue of poetical discourse, effects on the poetical imagination of a creative poet, and aesthetical brightening of an artistic poetical imagery. This study also shows that Ibn Tabatiba in his work "Eyar Ash shir" took the pretense (sana'a) as a basis on which based his judgmental criticism appraisals, giving priority to form rather than content, finally the study shows that while recognizing the importance of the later.
\end{abstract}

Keywords: Ibn Tabatiba, Word and Meaning, Artistic imagery.

$$
\begin{aligned}
& \text { النقديـة الأخــرى القديهــة والمعاصــرة، منـاقشــاً مـا }
\end{aligned}
$$

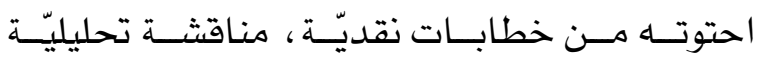

$$
\begin{aligned}
& \text { مقارنة ، تحاول الابتعاد عن الهوى التأثري الانفعـالي } \\
& \text { الـذاتي، الـذي كـان سهـة الكـثيرمسن الأحكـام } \\
& \text { والنظرات النقديّة العربية القديهـة ، هـذا إلى جانب } \\
& \text { اشتمال هذا المصدر وتطرّقه إلى عـدد مـن القضـايا } \\
& \text { والمقــولات النقديّة الحسـاســة الهامسـة ، مــن مثـل : } \\
& \text { إشكاليّة الصورة الفنية ، واللفظ والمعنى، إلى غـير } \\
& \text { ذلك من الإشكاليات التي كانت ومـا زالت، تُثير }
\end{aligned}
$$

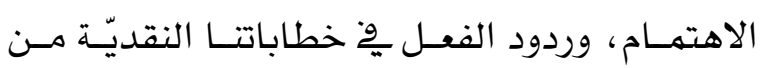

$$
\begin{aligned}
& \text { جهة رابعة. } \\
& \text { المناقشة } \\
& \text { أ- الجدلية الثنائية : اللفظ والمعنى } \\
& \text { وعلى الرغم من تلم الأصبهاني } \\
& \text { (الحموي، 19HV، 19 : بعا ) إلى بَدهية العلاقة } \\
& \text { الجدلية ما بين المعاني وألفاظها ، وتأكيده على أن } \\
& \text { يعـدّ كتـاب " عيـار الشـعر " لمؤلفــه محمــد } \\
& \text { بـن أحهـد أبـي الحسـن ابـن طباطبـا الأصــهاني } \\
& \text { (ت ب Fــ) من أبرز أمهات المصـادر العربيـة النقديـة } \\
& \text { القديهــة الـتي صُّنفت وِّ القــرن الرابــع الهجــري } \\
& \text { وأهمهـــا ، وتســتهدف هــذه الدراســة ِوْ إجرائهــا }
\end{aligned}
$$

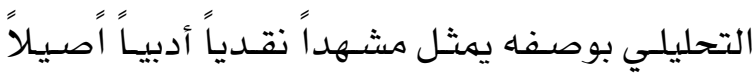

$$
\begin{aligned}
& \text { جاداً، يتوق إلى صياغة المعايير الأسـاسية من جهة ، } \\
& \text { ويسعى إلى بلورة القـوانـين الأصـولية النظريـة لمفهوم } \\
& \text { الثـعر العربيّ التقليـديّ (الككلاسـيكي) مـن جهـة } \\
& \text { ثانيـة. ولعـلّ مـن أبـرز مـا يميّز هـذا المصسـدر النقـدي }
\end{aligned}
$$

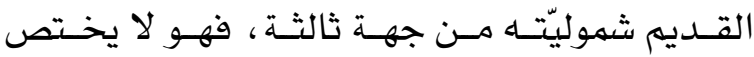

$$
\begin{aligned}
& \text { بدراسة شـاعر معين ، بـل هـو مؤلـف تنظيري يتـاول }
\end{aligned}
$$

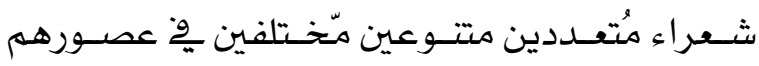

$$
\begin{aligned}
& \text { وأسـاليبهم ( قُمدماء ومُعَاصـرين) -آنـذاك- مقارنـة } \\
& \text { بيـنهم و محلّلـة ، كهمـا يعـرض لعـدد مــن المصــادر }
\end{aligned}
$$


فعيدُ صياغَتهما بأحسن مها كانا عليه، وكالصبّاغ الذي يصبغُ الثوبَ على ما رأى من

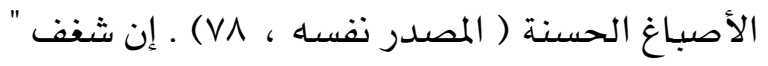
ابن طباطبا " بالشكل قد دفعه للخلط ما بين الشعر والنثر، من جهة، إلى الترويج لظاهرة

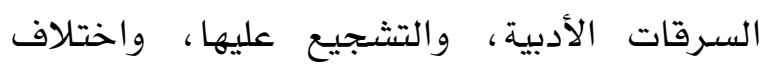
المسوّغات الإباحية لها، من جهة أخرى، يُضاف إلى الى الى الى

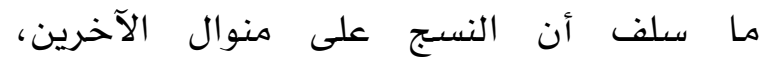

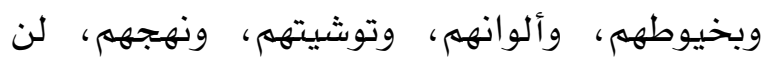

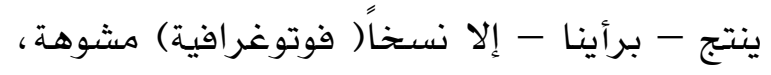
وأنماطاً أحاديَّة شاحبةً فقيرة، ونصوصاً مُقَلَّدة

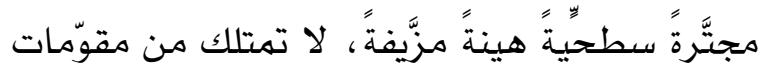

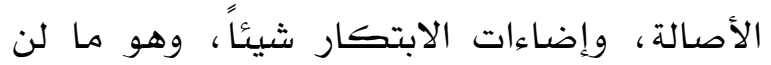

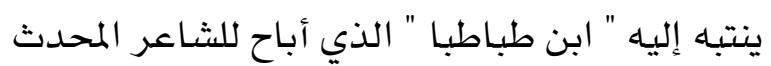

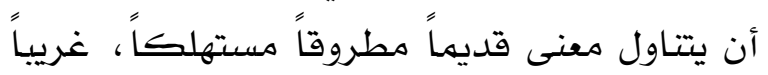

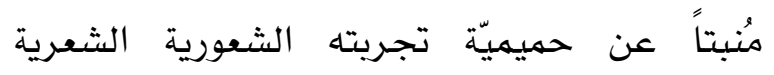

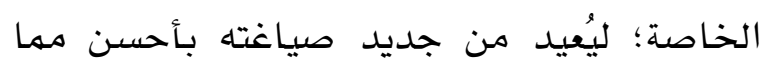

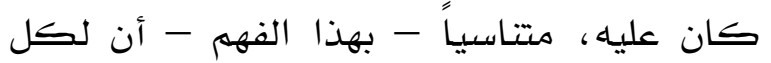
معنى خصوصيته البنائيّة التي تفرضها وتحدّدها

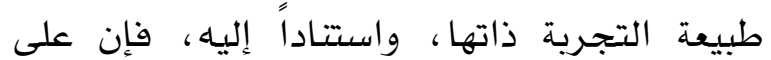

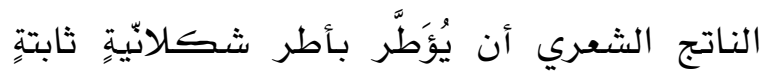

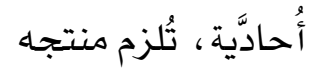

الخضوع لأصول النظم الآلي، وتقنيات ملتهن الصنّعة التقليدية الموروثة، التي تجبره - بدورها

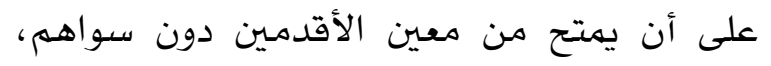

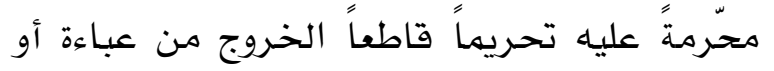

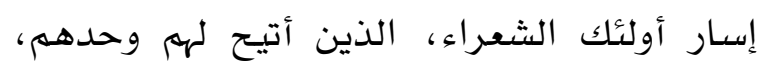

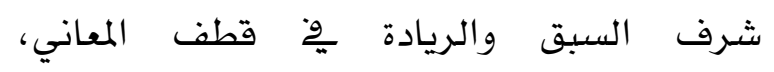

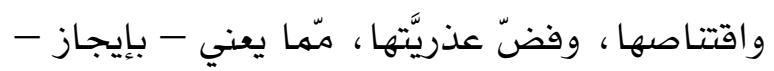

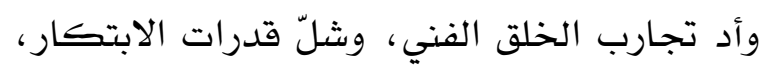

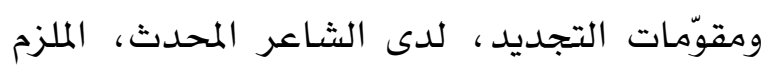
باعتهاد آليات نظمٍ سلطويّةٍ ، والخضوع لسننها

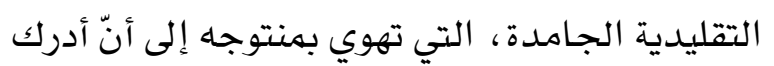

اللفظ جسه، روحه المعنى، وارتباطه كارتباط الروح بالجسم، يضعف ويقوى بقوته، إلا أن فهمه ظل دون مستوى الإحاطة الكلية الشمولية بهذه

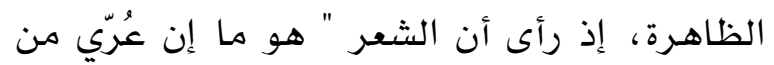

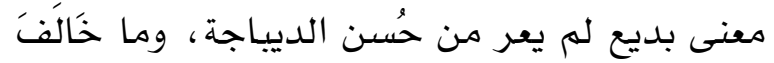

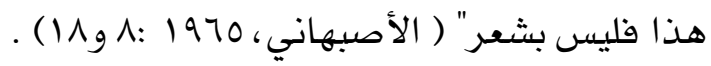
بهذا الشكل باعد " ابن طباطبا " بين بين المحتوى وشكله الخاص المتتاسب معه والمندغم بهن بهن

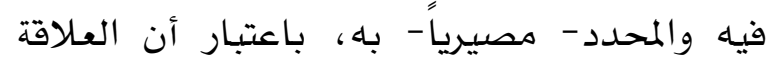
بينهما

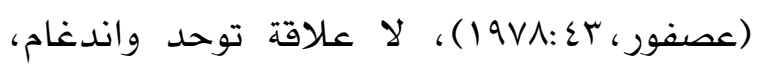

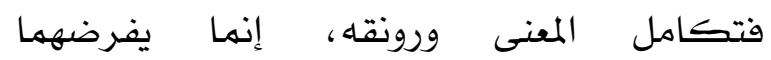

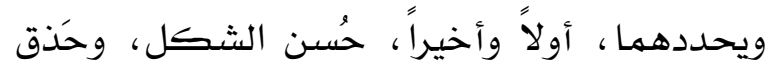
الرصف، وبديع الصنّعة ، بل إن الشكل ليبلغ من

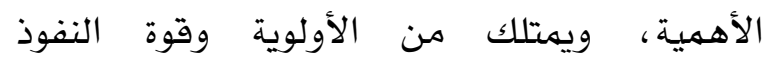
والسلطويّة، ما يجعله يسد الفراغ والخِواء، ويستر

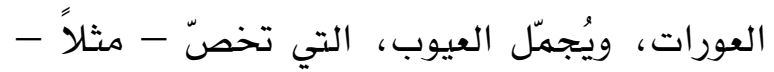

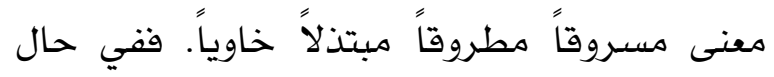

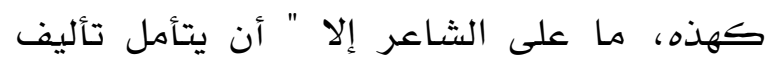

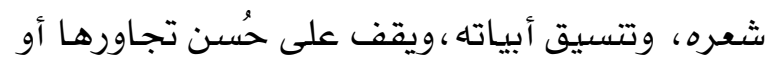

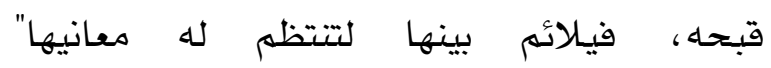
(الأصبهاني، 1970: ع 1 1 ). وبفصله المعنى عن الشكل آليّاً، يتجاهل ناقدنا خصوصية التجرية الشعرية، الملتحمة -

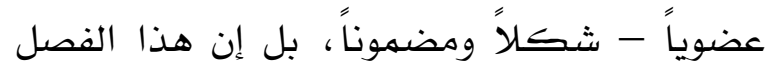

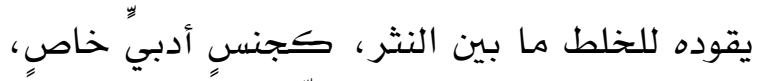

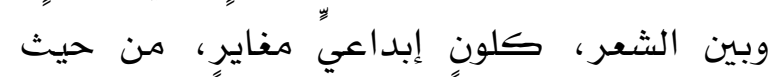

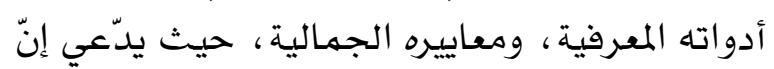

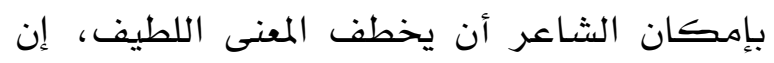

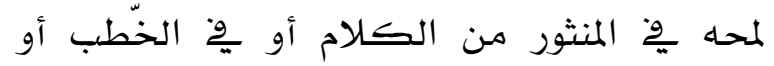

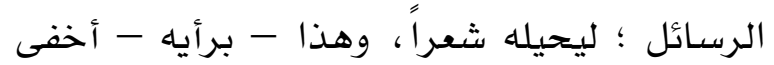

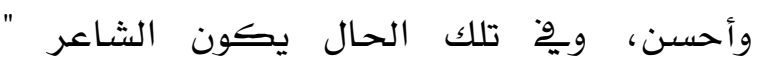

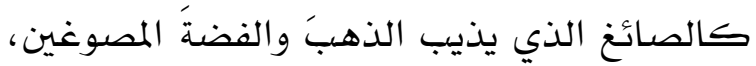


اللفظ وحده صوتاً دون معنى، أي لا يمكن على

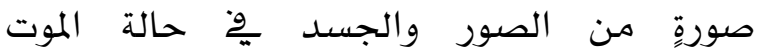
(الأصبهاني، V7: V7 ( ) ).

ولعل هذه الرؤية الذاتية الأحادية لإشكالية الشكل والمضمون تزداد خطورة، حين تدفع بناقدنا إلى تبرير السرقات الشعرية المستفحلة بحدةٍ وِّ نِتاجات الكثيرين من شعراء عصره المحدثين، الذين كانت مهماتهم - كما يرى- عسيرة

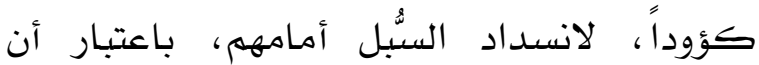
أسـافهم الأقدمين قد سبقوهم لجني المعاني

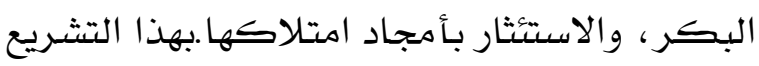
أشرع "ابن طباطبا" المجال على مصراعيه أهـا الشعراء المحدثين، كي يتكئوا على المعاني الموروثة القديمة، التي تداولها الشعراء الأسبقون، لاكوها لدرجة الاستهلاك والابتذال، شريطة توظيفها ِوْ سياقات أشعارهم المغايرة تاريخياً

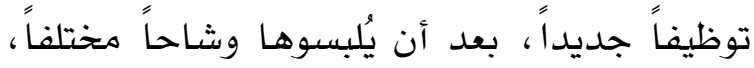

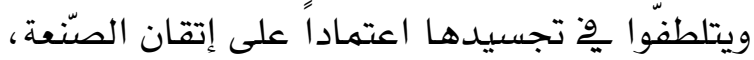
وبراعة التحايل، وتجميل السرقة، وتهويه المادة المسروقة، بحيث

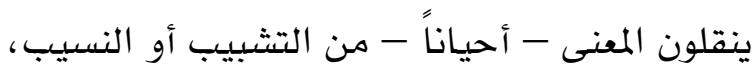

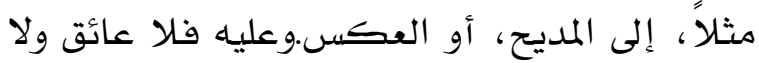

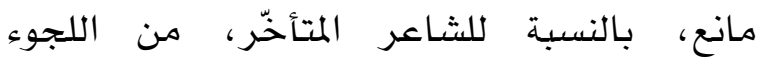
للسرقات الشعرية، عبر تتاول معانٍ مكررةٍ مستهلكةٍ سبقه الأقدمون إلى طرقها وعكسها، ، حسب رؤية " ابن طباطبا " الذي يُبيح مثل هذا الثربـ السطو والاستلاب، فيما لو تمّكن الشاعر لئح السارق، بسعة حيلته ودهائه، وبراعة صنعته، ودقة ولة ونس تزييفه، من إبراز تلك المعاني السلبية المبتذلة، وجلائها بأسلوبيّة مغايرة، وكسوةٍ " أحسن من الكسوة التي عليها " (الأصبهاني، 1970: NV و 1). وعلى النقيض، فإذا تمكّن الشاعر المحدث من تقكيك تلك المعاني من لُحمتها البنيويّة
الاجترار والركود والابتذال والبلى والرتوب، على

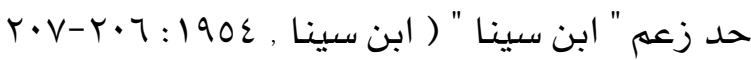
وهكذا يلخص " ابن طباطبا " إلى ان

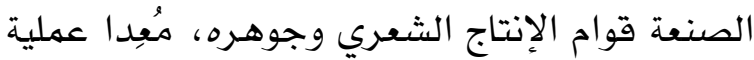
الخلق والإبداع الشعري مجرد حرفةٍ آلية، لا تتمايز إطلاقا - عن سائر الصناعات الحرفية النمطية، الأمر الذي قاده للفصل بين اللفظ والمعنى، وجعله لا يرى يِّ الشعر أكثر من صنعةٍ تتماثل وتتساوق مع المهن البسيطة: من حياكةٍ، ونسـجٍ، وتطريزٍ،

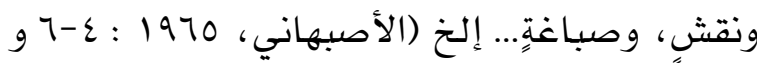

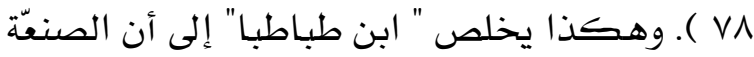

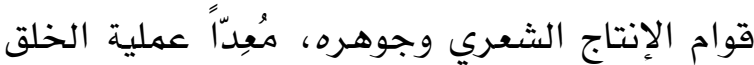
والإبداع الشعري مجرد حرفةٍ آليةٍ لا تتمايز إطلاقا- عن سائر الصناعات الحرفيّة النهطيّة، الأمر الذي قاده للفصل بين اللفظ والمعنى، وجعله

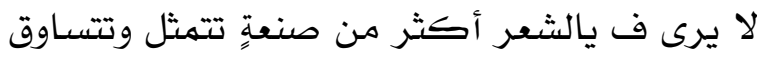
مع المهن العادية البسيطة: من حياكةٍ ونستِ وتطريزٍ، ونقشٍ، وصباغةٍ .... إلخ ( سـلام IV د.

إن فِصنَلً ميكانيكياً فَجَّاً كهذا، ليطرح

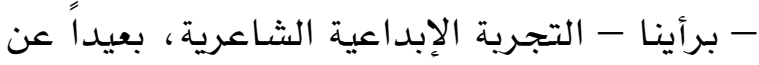
شروطها الإنسانية الدافئة، وأجوائها الطبيعية

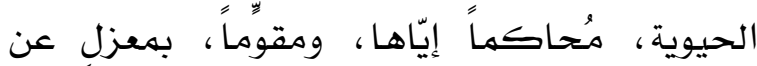

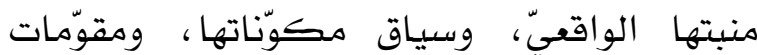
ظهورها، ونضجها وتكاملها ، وذاك ما يُعاكس اكس فلسفة الخلق الفنّي، ويتجاوز منطق الإبداع

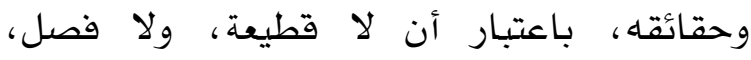

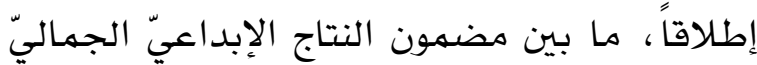

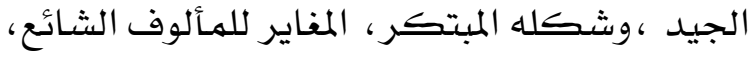
بل إن مثل هذا التصوّر لاستقلال أحدهما عن الآخر لا يتفق بِّ اللفظ المفرد، ولا سيما وأنَّ اللفظ، پِّ أصله وحقيقته" رمز لمعنى، ولا يقوم 


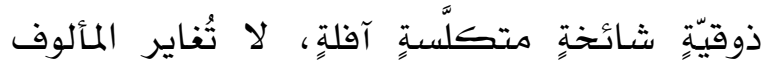
وتتجاوزه، ولا تتزاح عن إسـار الثابت المعهود

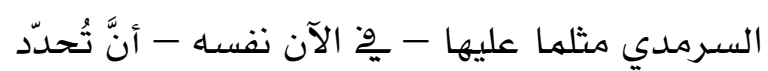

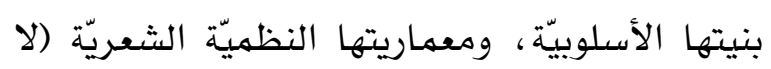

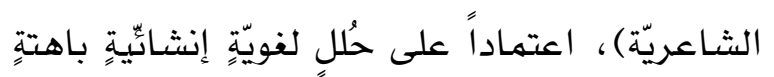

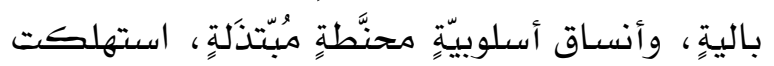

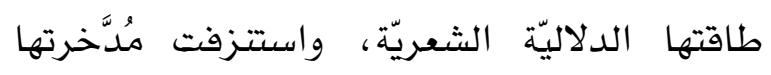

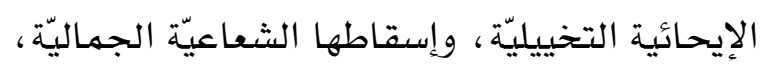

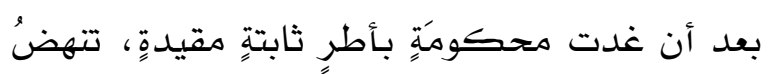

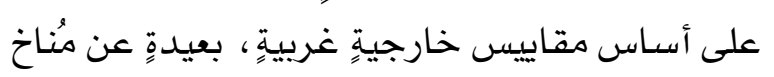

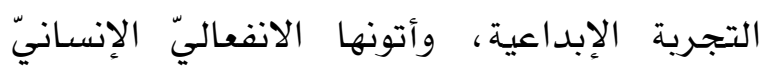

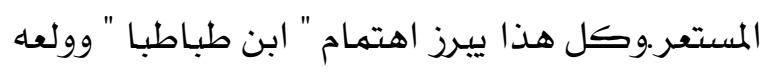

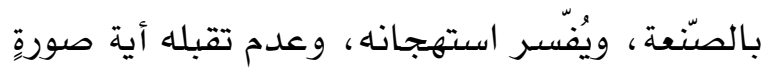

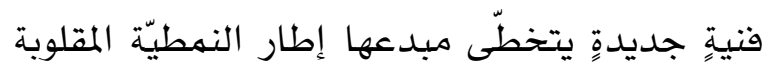

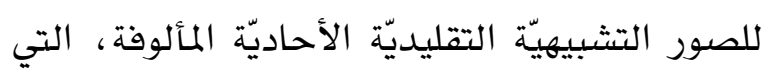
تراعي مشروعيّة التقارب الشكلي والتحلاقي الايدية المنطقي ما بين المشبّه والمشبّه بهاه، مثلما تُحتِّم

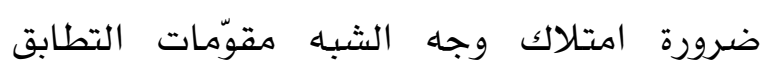
والانسجام ما بين تجلّياته التصويريّة البلاغيّة

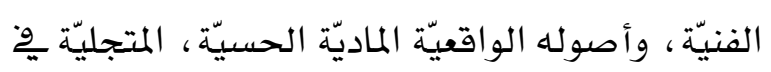

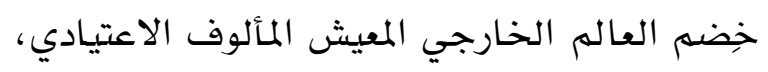
تلك الأصول التي لا بُدَّ أن تُشكّل الخيوط المُّل الأولية

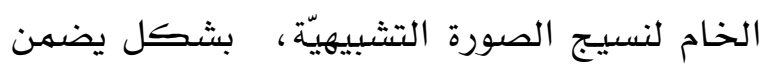

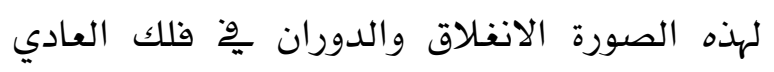

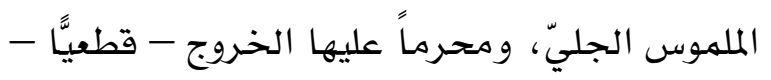

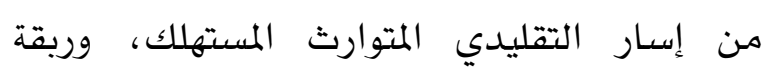

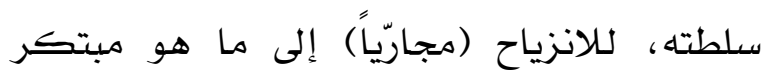

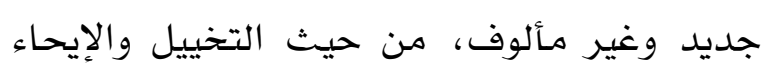

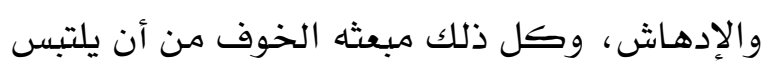

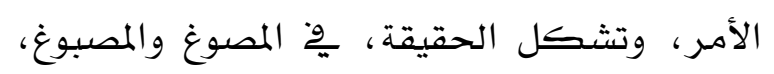

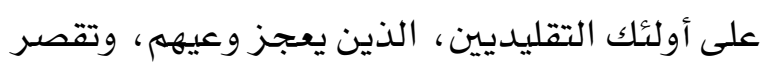

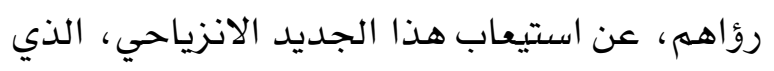

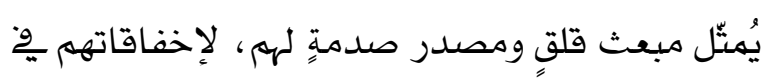

الأسلوبية الأولية، وانتزاعها من نسيج علاقاتها

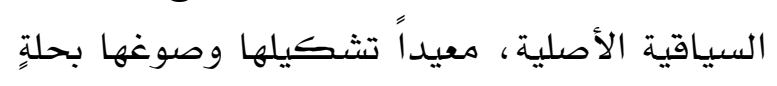

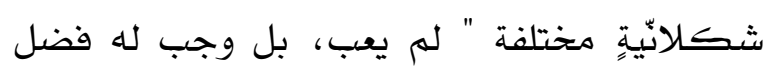

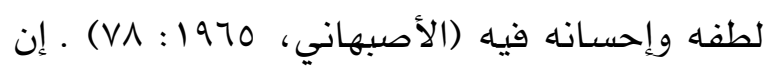

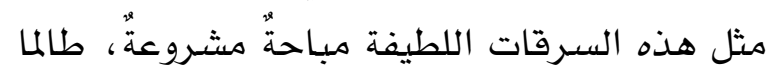

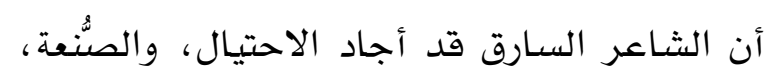

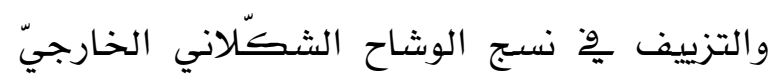
المصطنع، وخلعه على المعنى القديم، الذي تمت التهي

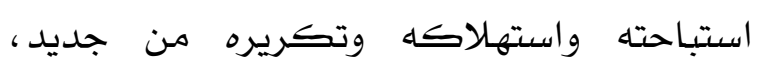

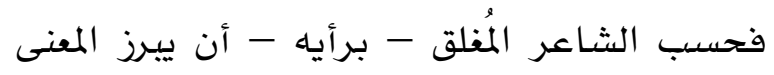

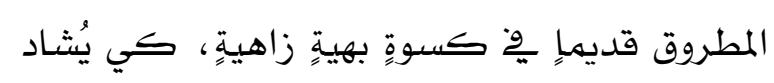

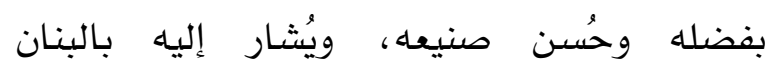

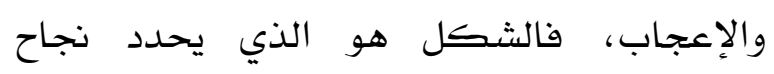

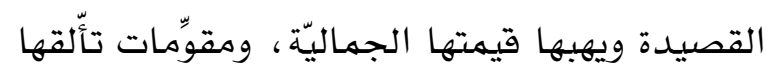

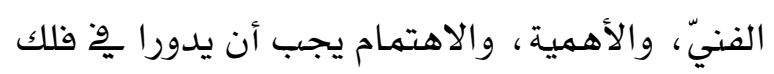

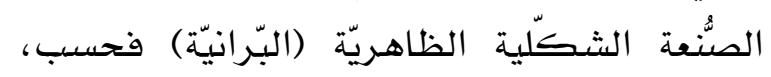

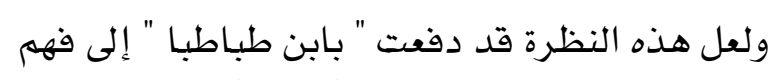

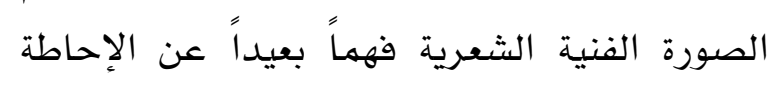

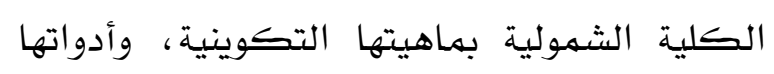

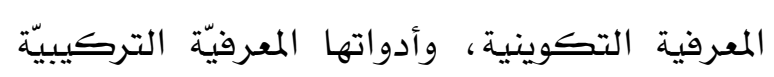

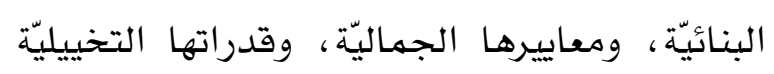

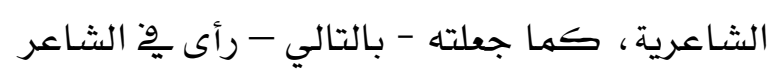

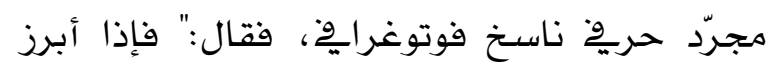

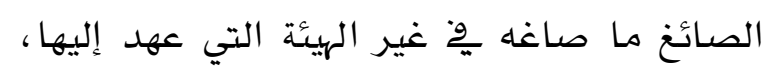

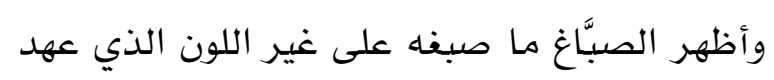

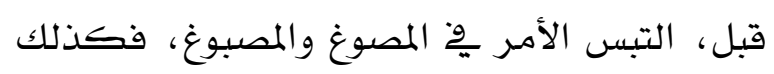

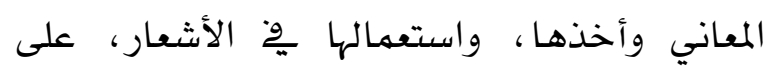

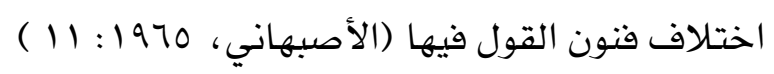
إن رؤية أحاديّة كهذه لتؤدي - برأينا - إلى الى دثر فعالّية الطاقة التخييليّة، وخفوت آحادية التوهِّج الجماليّ للصورة الفنيّة، التي عليها - برأي ناقدنا

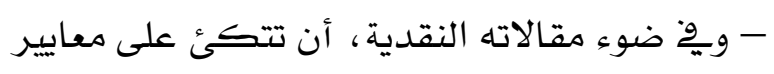




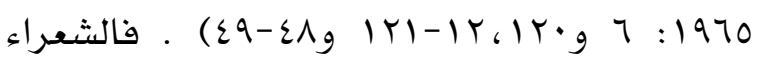

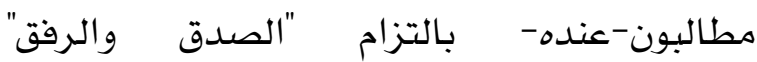

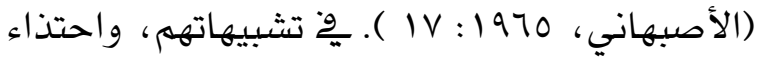
نهج أسـلافهم من الشعراء التقليديين، الذين

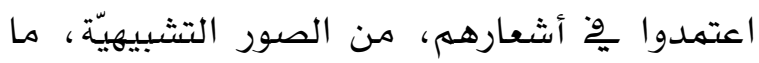

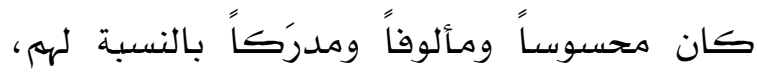

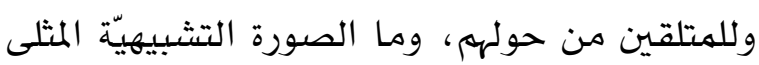
- برأيه - إلا تلك التي شكل هوله " الصدق "اللون

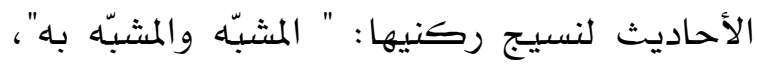
وجعلها تتطابق وحقيقة المشبّه باه، الكامن

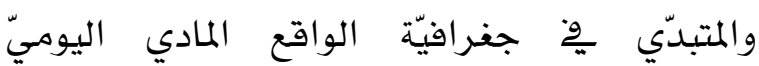

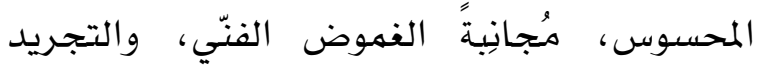

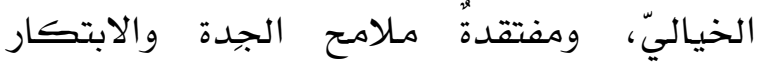

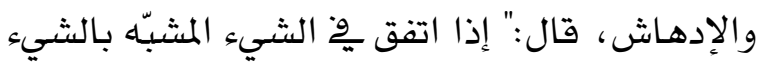

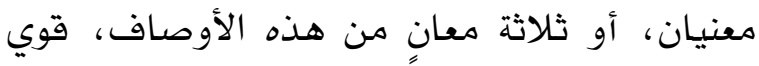

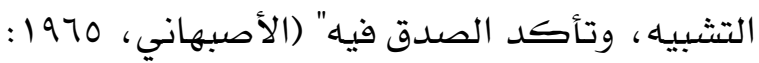

وبناءً على هذا الفهم، يهكن تمييز التشبيه

الصادق الجميل، من خلال ما يحويه من أدوات

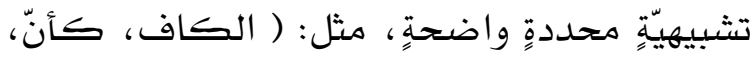
كَذا )، والتشبيه المقارب للصدق، محدو من خلال،

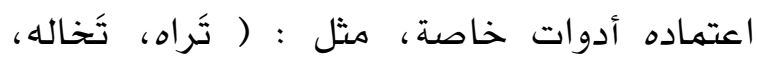

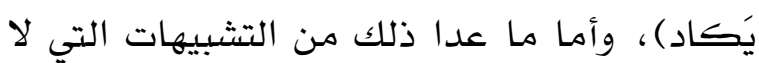
تشتهل، بِّ بنائها، على مثل الأدوات السابقة فليست بهقبولة إطلاقاً، وقال: "فها كان من من أن التشبيه صادقاً قلت وِّ وصفه، كأن، أو قُلتُ

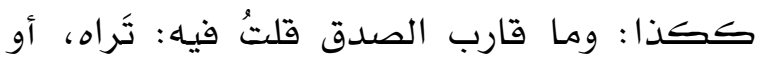

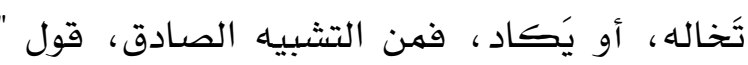

$$
\text { امرؤ القيس ( ت • • مه م)": }
$$

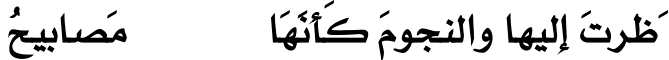

$$
\text { رُهبانِ تشبُّ لقفالٍ }
$$

فشبّه النجوم بهصابيح رُهبانٍ لفرط ضيائها وتعبّد الرُّهبان لمصابيحهم وقيامهم عليها؛ لتزهر
استيعابه، وتملّكه معرفياً وجمالياً، باعتبارهم

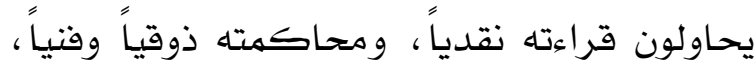
״ِ ضوء خطاباتهم البالية، وأدواتهم المعرفية الإجرائية الثائخة، ومعاييرهم الجمالية التقويميّة القاصرة التي تخطتها سيرورة الإبداع، وجعلتها

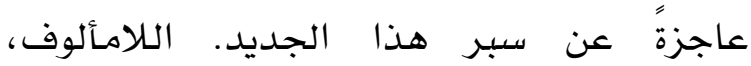

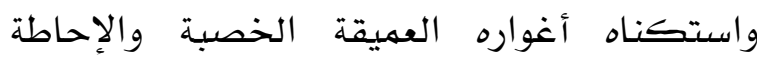
بهاهيّة إسقاطاته التخييليّة المعقدّة. ب-إثكالية قضية الصدق والكذب ِوْ الخطاب الشعري وأثرها على الخيال وتشكيل الصورة

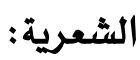

يمكن القول أن ابن طباطبا ألح ، ِِوْ " عِيار

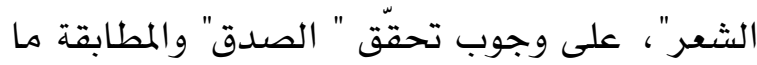
بين " الفنّي " و"الواقعيّ"، مؤكداً حتمية التزام

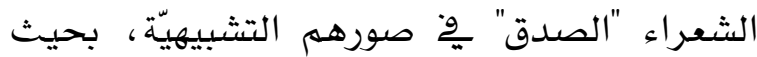
تغدو هذه الصور مقاربة، بل مطابقة، كلياً لمرآها

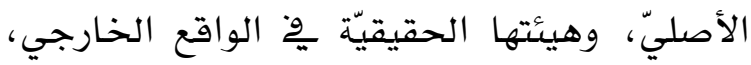

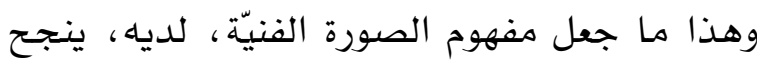
للوقوع ِِّْ شَرك المطابقة الآلية، ومزالق النسخخ

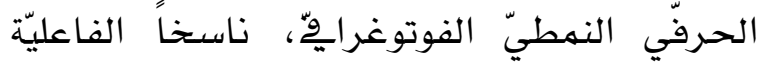
الإبداعيّة التصويريّة التخييليّة للمبدع والإبداع.فقي التوني سياق تذوقه الصور التشبيهيّة التقليديّة، التي أنتجها الشعر العربي القديم، وتحليلها ذوقياً وجمالياً، يهضي ليؤكد أن الشعراء الأسبقين (وهم الرّواد، والأنموذج، الأمثل للمحاكاة برأيه)

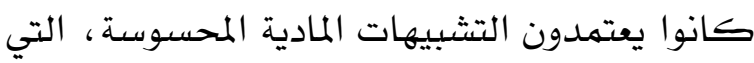

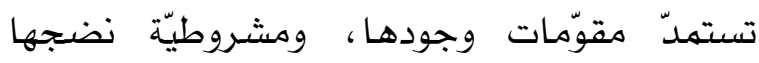

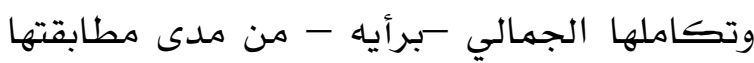

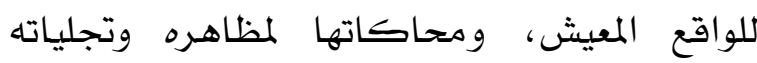
الخارجية الملموسة محاكاة آلية مباشرة، ترتكز

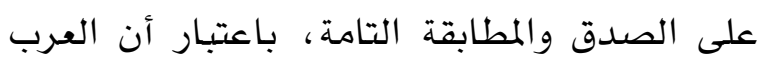

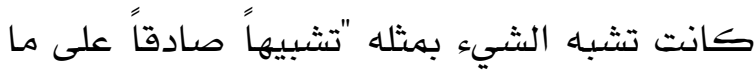
ذهبت إليه ِِ معانيها التي أرادتها" (الأصبهاني، 
-عنده- قرينة الإشـارات البعيدة والحكايات الغلّقة

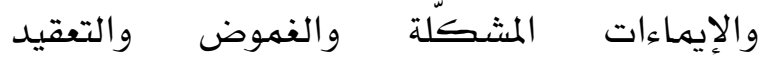

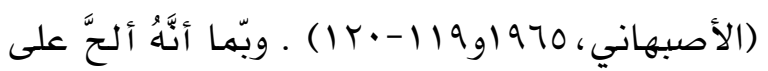

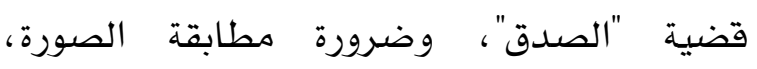

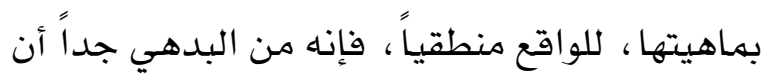

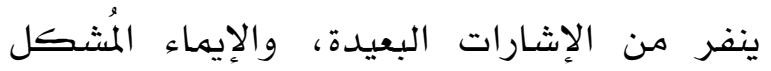

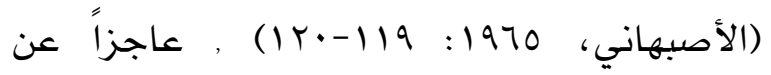
التقاط الأبعاد الإيحائية التخييليّة، وإدراك المشهد الإهد

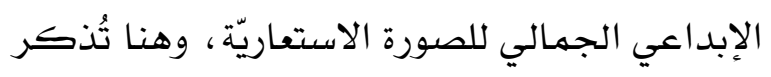
قصة الاستعارات عند أبي تمام ورّدها. وِِّ السياق هذا نجده أكّدَ ضرورة التزام

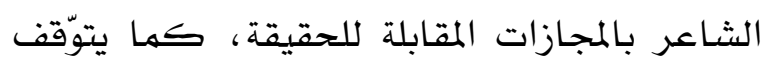

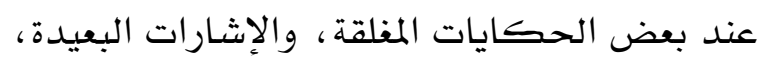

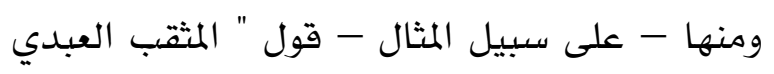

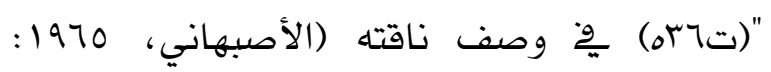

$:(1) \cdot-119$

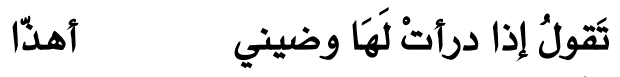
دينه أبدًا وديني

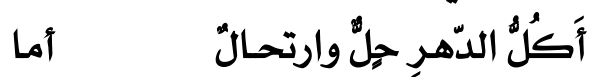
يُبْقي عَكَيَّ ولاَ يقيني الِِّي علّق على هذين البيتين بالقول : فهذه الحكاية كلها عن ناقته من المجان المبناز بالهول

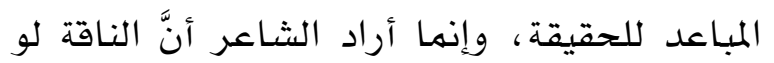
تكلّمَت لأعريت عن شكواهـا بهثل هذا القول،

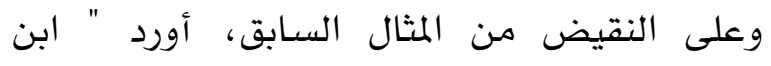

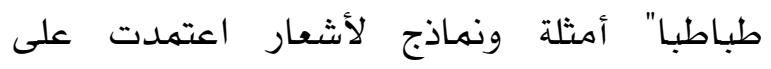
المجازات ما يقارب الحقيقة وتُحاكي المظاهر

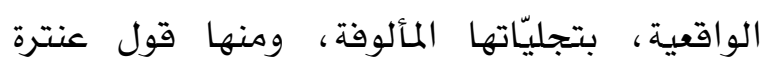
(ت $:(171$

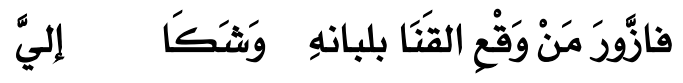
بعبّرة وتحمحم من مور
إلى الصبح، فكذلك النجوم زاهرة طوال الليل،

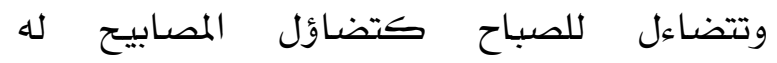
(الأصبهاني، 1970 : • (9): أمّا التشبيهات غير الصادقة فيهتّلها قول " خفاف بن ندبة "(ت • r ه):

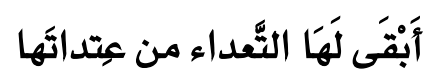
وَمتونها كيخوط الكتّان

والسبب پِّ عدم صدقه عود إلى أنه قصد

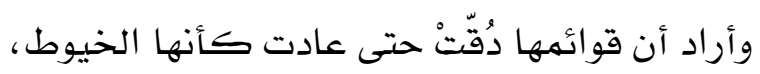
وأراد ضلوعها فقال : متونها"( الأصبهاني، 1970 :

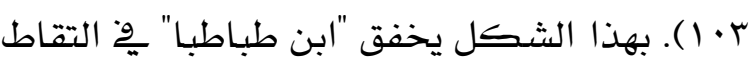

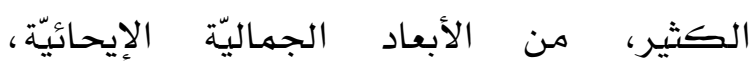

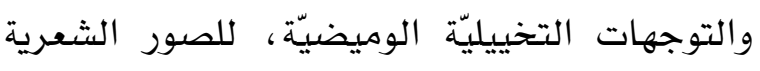

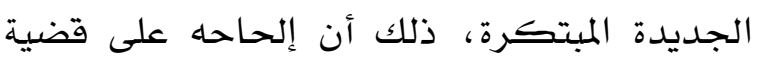

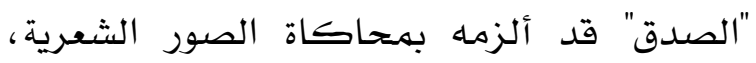

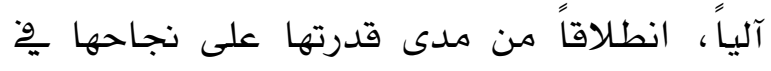

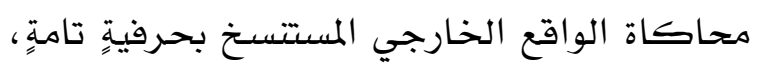

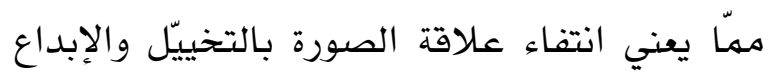

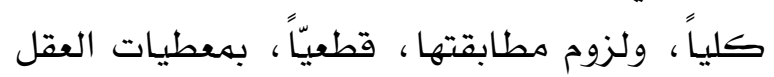

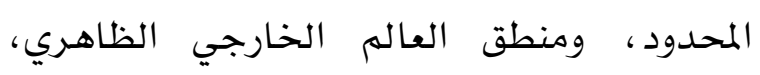

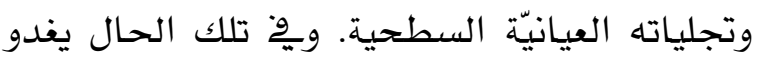

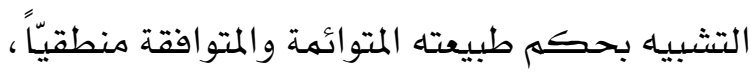

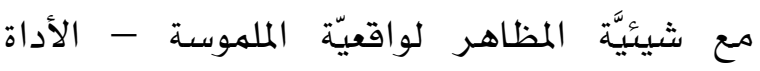

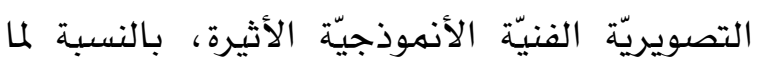

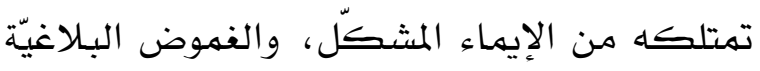

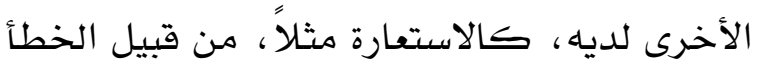

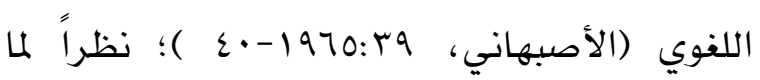

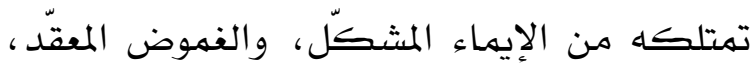

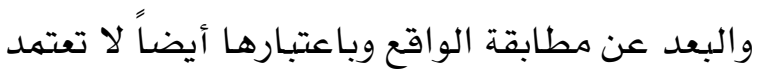

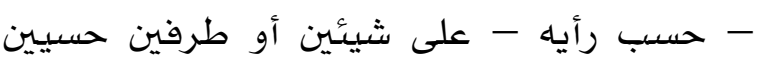
مألوفين منطقيين. لهذ فقد استهجن استعارات "أبي

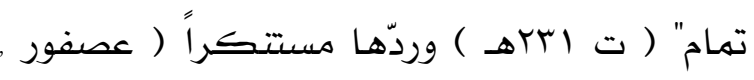

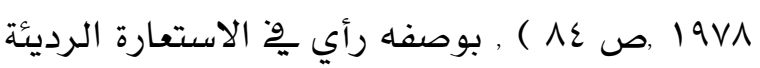


بين طريخٌ الصورة التشبيهية الفنية، قد جعله يعجز عن إدراك الفعالية التخييليّة والطاقة الإيحائيّة ، ويخفق ״ِ معايشة حرارة التجرية الشعورية -

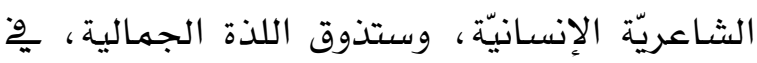

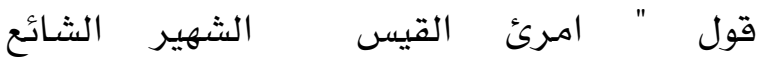

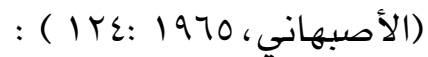

\section{وَكَيلِ كَموج البحرِ آرخَى سُدوله عَلَّ بأنواع الهموم ليبتلي}

باعتبار أن الصورة الفنيّة - هُنا - تُشكّل

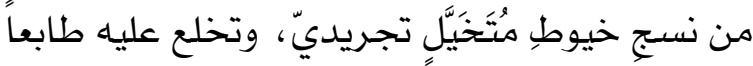

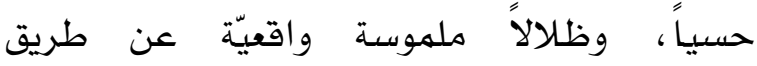

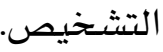

مهّا سلف يتأكسَّ ، جلّياً، أن اهتمام ابن

طباطبا ينحصر ، أولاً وأخيراً ِِّْ إبراز منطق اهن

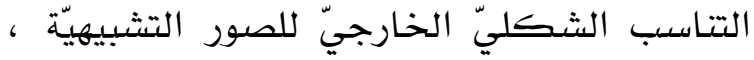
وجلاء سرّر التجانس البنيويّ اللفوي، مع إهماله -

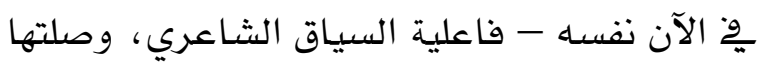

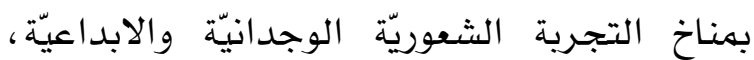
وكنه محتواها.

وعلى سبيل المثال ، لا الحصر، نجده يتوقف عند " امرئ القيس "قوله (المصدر نقسهاه , ص ص لمص : ( IrO- IrE

\section{كَأَّيّ لَمْ أَركبْ جَواداً للدّة

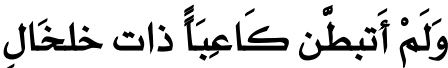

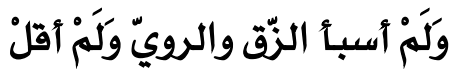

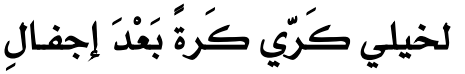

مُشيراً إلى أن الشـاعر لو وضع مصراعُ كُلّ بيتٍٍ منهما ٌِِ موضع الآخر ، لكان ذلك أشكل

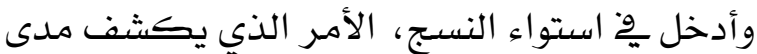

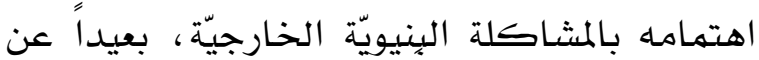
طبيعة مدلول الإيحائي الشاعريّ، والمخزون

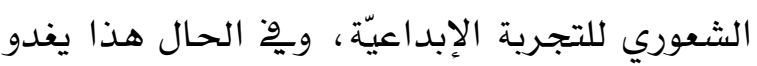

والواقع أن مثل هذا الفهم لماهيّة الصورة

الفنية، ومقوّماتها الجماليّة، يُلفي فعالية التخييل الإبداعي، ويئد شتحناته التأثيريّة ، وتوهّجاته

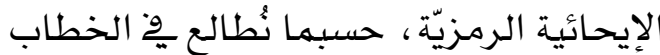

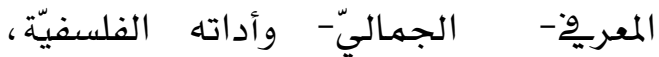
وأصوله النقديّة، لدى كل من الفيلسوفين

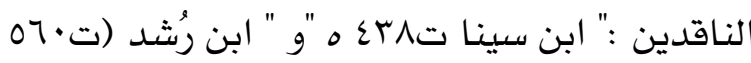
. (。

فقد أكد الفيلسوف أن " المحاكاة " تعني : إيراد مثل الشيء، وليس هو " هو " (الأصبهاني، ل 1970:YV.

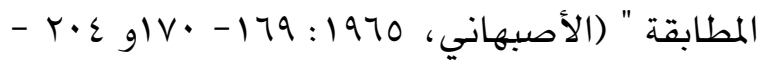

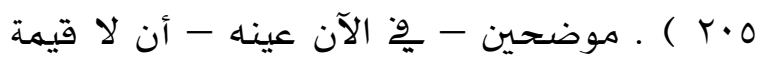
معرفيّة وجماليّة لمحاكاة المطابقة، التي ليست أكثر من مادة خام صماء، لا تُتير الاتفعال

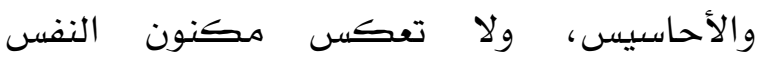
وأغوارها، إضافة إلى أنها تفتقد الأبعاد المعرفيّة

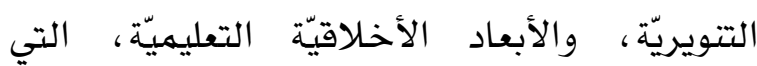
تكسب الشعر مبررات وجوده، وتمنحاه شرعيته، وقيمته، وأسرار استمراريته وخلوده. من هنا مضى الفيلسوفان ليصرّحا : " أن كل تشبيهٍ وحكاية

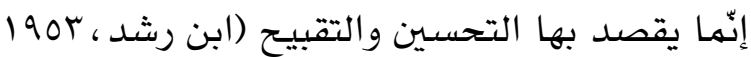
، 17-70 ) ـ مبيّنين أنه قد: "يوجد للتشبيه بالقول فصلٌ ثالثُ، وهو التشبيه الذي يُقصد بهاه مطابقة

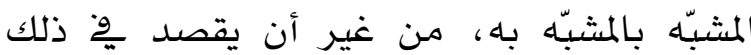

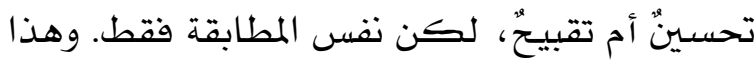

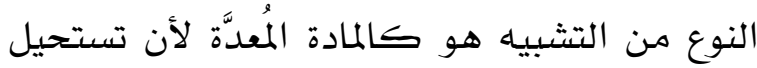

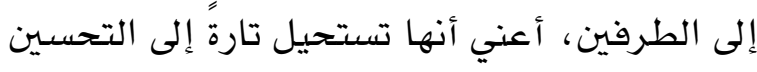

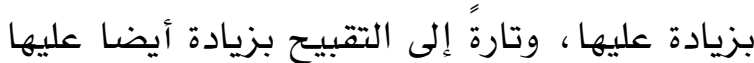

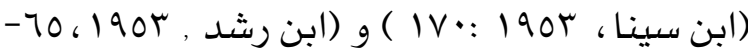

إن إلحاح "ابن طباطبا" على وجوب تحقّق "

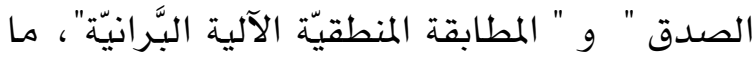


جاهزة مُسنتهُلّكَةٍ ، لا يمكن بوساطتها توظيف

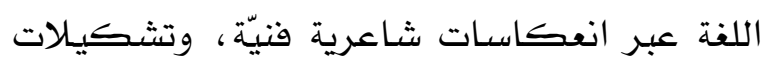

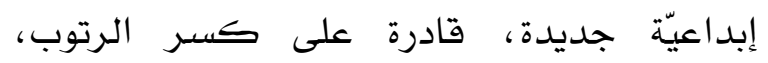
وتحطيم السائد البائد؛ لاختراق ما هو مألوف إدئ

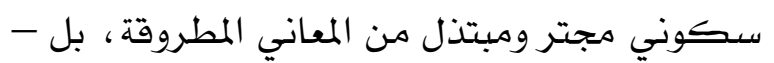
على العكس- تتهض تلك الأطر الجامدة كقيود

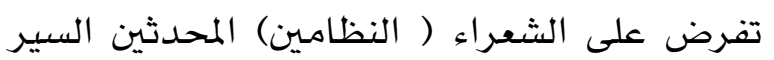
على هدي عمود الشعر العربيّ التقليديّ، ومتابعة

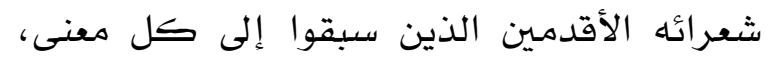

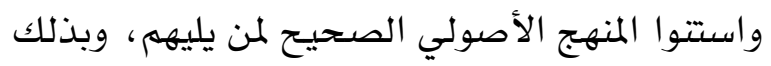

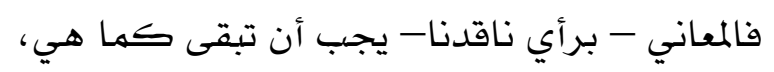

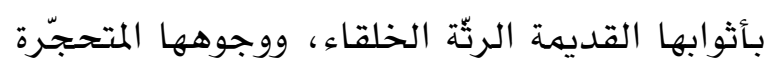

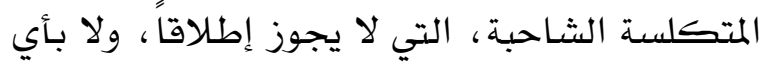

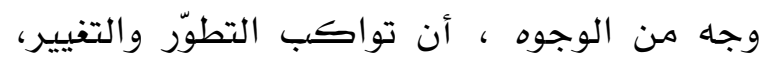

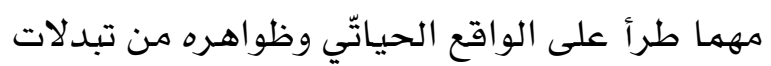
جوهريّة معقدة حاسمة.
أحسن الشعر - برأيه - ما أوقع فيه الكلام مواقعه الشكلية المحددة المقولبة ، بهعزلٍ عن اهن

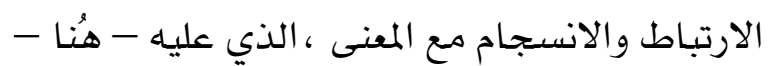

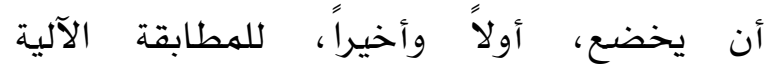

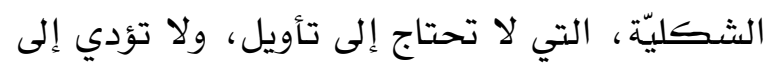

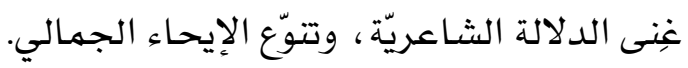

\section{الخلاصة}

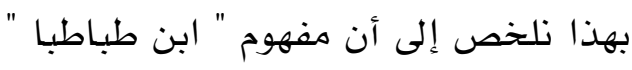

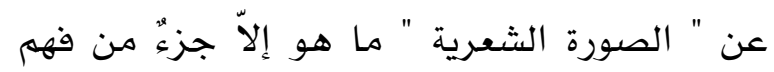

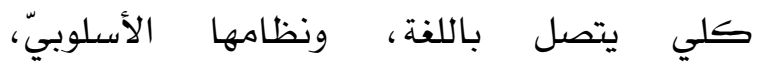

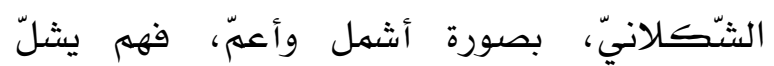

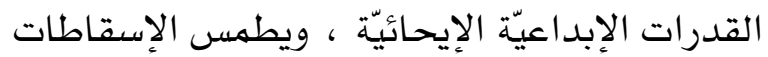

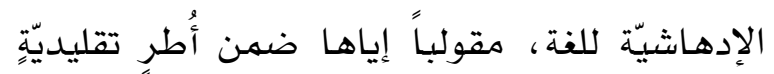

\section{المراجع}

الأصبهاني ,ابن طباطبا ( مُحمّد بن أحمد بن الحسن ),عيار الشعر، تحقيق طه الحاجري ،ومحمد زغلول سلاّم

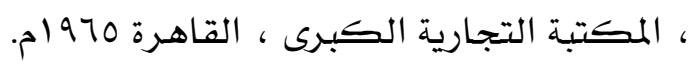

الحموي ، ياقوت , معجهم الأدباء ، طبعة مُحمّد فريد الرفاعي، دار المأمون ، وزارة المعارف القومية، مصر . $19 \mathrm{Vr}$ ابن رُشَد ( أبو الوليد مُحمّد بن أحمد بن مُحمّد ) , تلخيص كتاب أرسطو طاليس وِِ الشعر : تحقيق ومراجعة

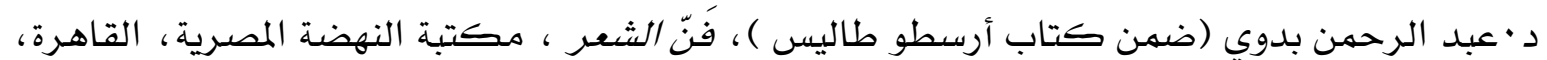
. $190 r$ سـلام ، هُحمّد زغلول , تاريخ النقد الأدبي والبلاغة حتى القرن الرابع الهجبري ، دار المعارف الإسكندرية ،د.ت ابن سينا ( أبو علي الحسين بن عبد الله) , الخطابة من كتاب الشفاء، تحقيق مُحمّد سليم سالم ،وزارة

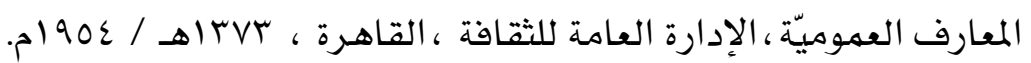

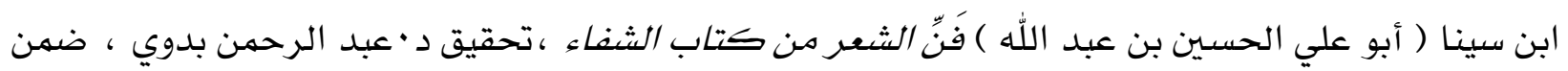

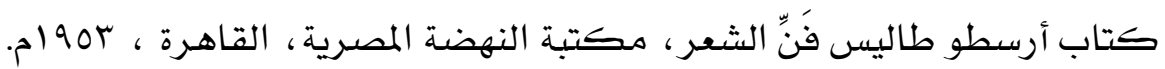
عصفور ، د. جابر أحمد , مغهوم الشعر - دراسة فِ التراث النقدي ، دار الثقافة للطباعة والنشر، القاهرة ، . $19 \vee \wedge$ 